\title{
Riociguat: a soluble guanylate cyclase stimulator for the treatment of pulmonary hypertension
}

This article was published in the following Dove Press journal:

Drug Design, Development and Therapy

13 April 2017

Number of times this article has been viewed

\section{Tian-Yu Lian \\ Xin Jiang \\ Zhi-Cheng Jing}

State Key Laboratory of

Cardiovascular Disease, Fuwai Hospital, National Center for

Cardiovascular Diseases, Chinese

Academy of Medical Sciences and

Peking Union Medical College, Beijing,

People's Republic of China
Correspondence: Zhi-Cheng Jing State Key Laboratory of Cardiovascular Disease, Fuwai Hospital, National Center for Cardiovascular Diseases, Chinese Academy of Medical Sciences and Peking Union Medical College, No 167, Beilishi Road, West District, Beijing 100037, People's Republic of China

Tel +861088396018

Fax +86I0883960I6

Email jingzhicheng@vip.163.com
Abstract: Despite advances in treatments and improved survival, patients with pulmonary hypertension still experience poor exercise and functional capacity, which has a significant detrimental impact on their quality of life. The nitric oxide (NO)-soluble guanylate cyclase (sGC)-cyclic guanosine 3',5'-monophosphate (cGMP) pathway has been shown to play an important role in cardiovascular physiology, especially in vasodilation and pulmonary vascular tone. The oral sGC stimulator riociguat has a dual mode of action on the NO-sGC-cGMP pathway: direct stimulation of $\mathrm{sGC}$ independent of $\mathrm{NO}$ and indirect simulation via sensitization of sGC to endogenous NO. Riociguat is now licensed in $>50$ countries worldwide, including in Europe, the USA, Canada, and Japan. Approval for the treatment of pulmonary arterial hypertension (PAH) was based on Phase III data from the PATENT studies, in which riociguat significantly improved exercise capacity, pulmonary vascular resistance, a range of secondary end points, and hemodynamic parameters in patients with symptomatic PAH. In the Phase III CHEST studies, riociguat consistently improved exercise capacity in patients with inoperable chronic thromboembolic pulmonary hypertension (CTEPH) or persistent/recurrent CTEPH after pulmonary endarterectomy and is now the only drug to be approved for this indication. Riociguat was well tolerated in long-term studies of PAH and CTEPH. This review describes the role of the NO-sGC-cGMP pathway in the pathophysiology of pulmonary hypertension, and reviews the clinical efficacy and safety of riociguat in patients with $\mathrm{PAH}$ and inoperable or persistent/recurrent CTEPH. Based on its demonstrated efficacy and established safety profile, riociguat is a promising treatment option for patients with $\mathrm{PAH}$ and CTEPH.

Keywords: CTEPH, PAH, pulmonary hypertension, riociguat, sGC stimulator

\section{Introduction}

Pulmonary hypertension $(\mathrm{PH})$ is a pathophysiological disorder that may involve multiple clinical conditions and can complicate the majority of cardiovascular and respiratory diseases. ${ }^{1}$ Group 1 PH comprises pulmonary arterial hypertension (PAH), a life-threatening disease characterized by increased pulmonary vascular resistance (PVR) due to progressive remodeling of the pulmonary vasculature, which can ultimately lead to right heart failure (HF) and death. ${ }^{1-3}$ Before the development of targeted PAH-specific drugs, the prognosis of patients was usually poor, with a median survival of only 2.8 years from the time of diagnosis. ${ }^{4}$ Recent advances in treatments for PAH have improved survival, but many patients still experience poor exercise and functional capacity and symptoms such as shortness of breath, chest pain, and fatigue, which worsen health-related quality of life. ${ }^{5}$

Other classes of PH include PH due to left HF (Group 2), PH due to lung diseases and/or hypoxia (Group 3), chronic thromboembolic pulmonary hypertension (CTEPH; Group 4), and PH with unclear and/or multifactorial mechanisms (Group 5). ${ }^{1}$ 
There is a substantial unmet need in the treatment of Group 4 $\mathrm{PH}-\mathrm{CTEPH} .{ }^{1} \mathrm{CTEPH}$ is a rare but life-threatening condition that is viewed as a complex "dual" vascular disorder involving obstruction of the pulmonary vasculature by organized thromboembolic material and also remodeling of small distal arteries in non-occluded areas. ${ }^{6}$ Pulmonary endarterectomy (PEA) is the treatment of choice for CTEPH in eligible patients. ${ }^{1}$ However, some patients are ineligible for surgery and others develop persistent/recurrent $\mathrm{PH}$ after PEA, requiring alternative/further treatment. Similarities in the signaling pathways involved in the pathophysiology of $\mathrm{PAH}$ and CTEPH suggest that these patients may benefit from PAH-specific therapies. ${ }^{7-9}$

One of the major pathways thought to be involved in the pathophysiology of $\mathrm{PH}$ is the nitric oxide (NO)-soluble guanylate cyclase (sGC)-cyclic guanosine monophosphate (cGMP) pathway. ${ }^{10-12}$ This article describes the role of the NO-sGC-cGMP pathway in the pathophysiology of $\mathrm{PH}$, and reviews the clinical efficacy and safety of the sGC stimulator riociguat in patients with $\mathrm{PAH}$ and inoperable or persistent/recurrent CTEPH and preliminary investigations in other PH etiologies.

\section{The NO-sGC-cGMP pathway and riociguat's mechanism of action}

cGMP is a pivotal second messenger controlling dilation and cellular proliferation within the vascular wall to maintain pulmonary vascular tone. NO is produced in endothelial cells with the involvement of several cofactors, such as asymmetric dimethylarginine (ADMA) and tetrahydrobiopterin (Figure 1). ${ }^{10}$ It diffuses to smooth muscle cells, where it activates the intracellular enzyme sGC, which in turn catalyzes the conversion of guanosine- 5 '-triphosphate to cGMP. The primary route of NO synthesis is the oxidation of the amino group of L-arginine, catalyzed by NO synthases (NOSs). Reductions in NO, and subsequently cGMP, can thus increase the pressure within the pulmonary circulation. Elevated levels of ADMA, which competes with L-arginine for NOS-binding sites but does not activate the enzyme, can impair NO synthesis. ${ }^{13}$

The production of cGMP is stimulated by NO via the NO-sGC-cGMP pathway (Figure 2). ${ }^{11} \mathrm{sGCs}$ are found in cytosolic fractions of the cell and are activated by NO. This is in contrast to membrane-bound guanylate cyclases (GCs), which are activated by natriuretic peptide receptors such as GC-A and GC-B. ${ }^{14}$ The distribution of GC proteins across various cells is isoform specific.

sGC is a heme-containing heterodimer with various isoforms composed of two homologous subunits: $\alpha$ and $\beta$. The

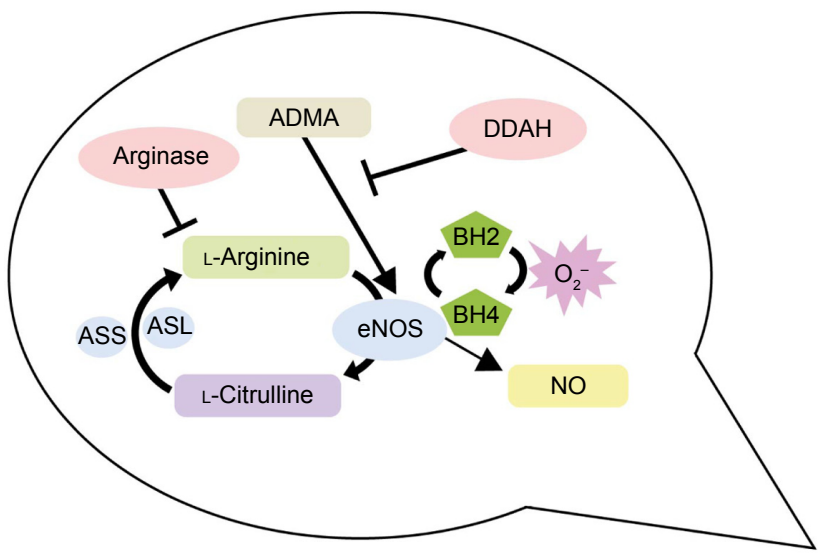

Figure I Generation of NO.

Notes: Reprinted with permission from the American Thoracic Society. Copyright (c) 2016 American Thoracic Society. Klinger JR, Abman SH, Gladwin MT. Nitric oxide deficiency and endothelial dysfunction in pulmonary arterial hypertension. $A m$ J Respir Crit Care Med. 2013; I88(6):639-646..$^{10}$ The American Journal of Respiratory and Critical Care Medicine is an official journal of the American Thoracic Society.

Abbreviations: ADMA, asymmetric dimethylarginine; ASL, argininosuccinate lyase; ASS, argininosuccinate synthase; $\mathrm{BH}$, dihydrobiopterin; $\mathrm{BH} 4$, tetrahydrobiopterin; $\mathrm{DDAH}$, dimethylarginine dimethylaminohydrolase; eNOS, endothelial nitric oxide synthase; $\mathrm{NO}$, nitric oxide; $\mathrm{O}_{2}^{-}$, superoxide anion.

most common isoform is the $\alpha 1 \beta 1$ protein. ${ }^{15}$ The isoforms of sGC are important in different physiological processes. For example, the $\alpha 1 \beta 1$ isoform plays a primary role in the mediation of vasodilation, ${ }^{16}$ including NO-mediated pulmonary vasodilation. ${ }^{17,18}$ The active catalytic site of sGC lies at the interface between the $C$-terminal domains of the two subunits. sGC is very sensitive to allosteric regulation. Binding of NO to sGC leads to structural changes in the helix $\alpha \mathrm{F}$ that activates the $C$-terminal catalytic domain. ${ }^{19,20}$ NO binding leads to increases in the synthesis of cGMP of approximately two orders of magnitude. cGMP targets, including phosphodiesterases (PDEs), ion-gated channels, and cGMP-dependent protein kinases (PKGs), participate in several physiological functions, such as vasodilation, platelet aggregation, and neurotransmission. ${ }^{21-23}$

The role of $\mathrm{sGC}$ in the production of cGMP makes it a potential target for treatments that aim to cause vasodilation and reduce blood pressure in the pulmonary circulation, as is required in PAH. The NO-sGC-cGMP pathway is a crucial mechanism in the pathogenesis of $\mathrm{PAH} .^{2}$ Inhibitors of PDE type 5 (PDE5), such as sildenafil and tadalafil, prevent PDE5 from degrading cGMP and have been used as clinical therapy of PAH for many years. ${ }^{1}$ It thus follows that agents acting to directly stimulate the production of cGMP by increasing the activity of sGC could have a potent effect in the treatment of PAH.

Riociguat is the first-in-class sGC stimulator with a dual mode of action: it stimulates sGC directly, independent of $\mathrm{NO}$, and also sensitizes sGC to endogenous NO by stabilizing 


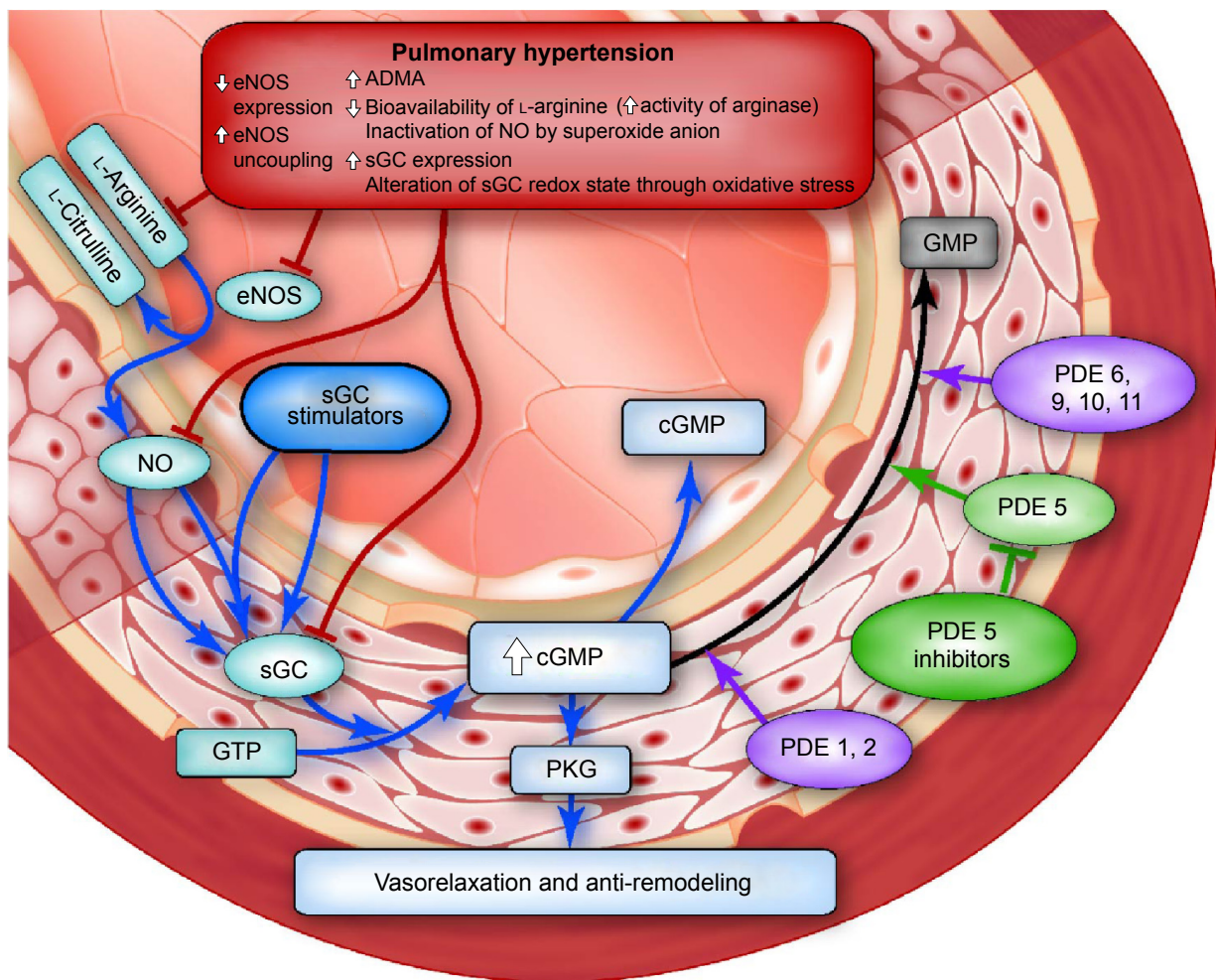

Figure 2 The NO-sGC-cGMP pathway.

Notes: Reprinted with permission from Stasch JP, Pacher P, Evgenov OV. Soluble guanylate cyclase as an emerging therapeutic target in cardiopulmonary disease. Circulation. 20II;I23(20):2263-2273." http://circ.ahajournals.org/. Promotional and commercial use of the material in print, digital or mobile device format is prohibited without the permission from the publisher Wolters Kluwer. Please contact healthpermissions@wolterskluwer.com for further information."

Abbreviations: ADMA, asymmetric dimethylarginine; cGMP, cyclic guanosine monophosphate; eNOS, endothelial nitric oxide synthase; GMP, guanosine monophosphate; GTP, guanosine triphosphate; NO, nitric oxide; PDE, phosphodiesterase; PKG, cGMP-dependent protein kinase; sGC, soluble guanylate cyclase.

NO-sGC binding, leading to increased intracellular cGMP levels (Figure 3). ${ }^{11,12,24-26}$ Studies in mouse and rat models have shown that riociguat effectively reduces $\mathrm{PH}^{27}$ and reverses the associated right heart hypertrophy and ventricular remodeling. ${ }^{28}$ Riociguat has also been shown to markedly improve survival and attenuate systolic dysfunction, as well as target fibrotic tissue remodeling, in salt-sensitive Dahl rats. ${ }^{29}$ This may be the pathophysiological

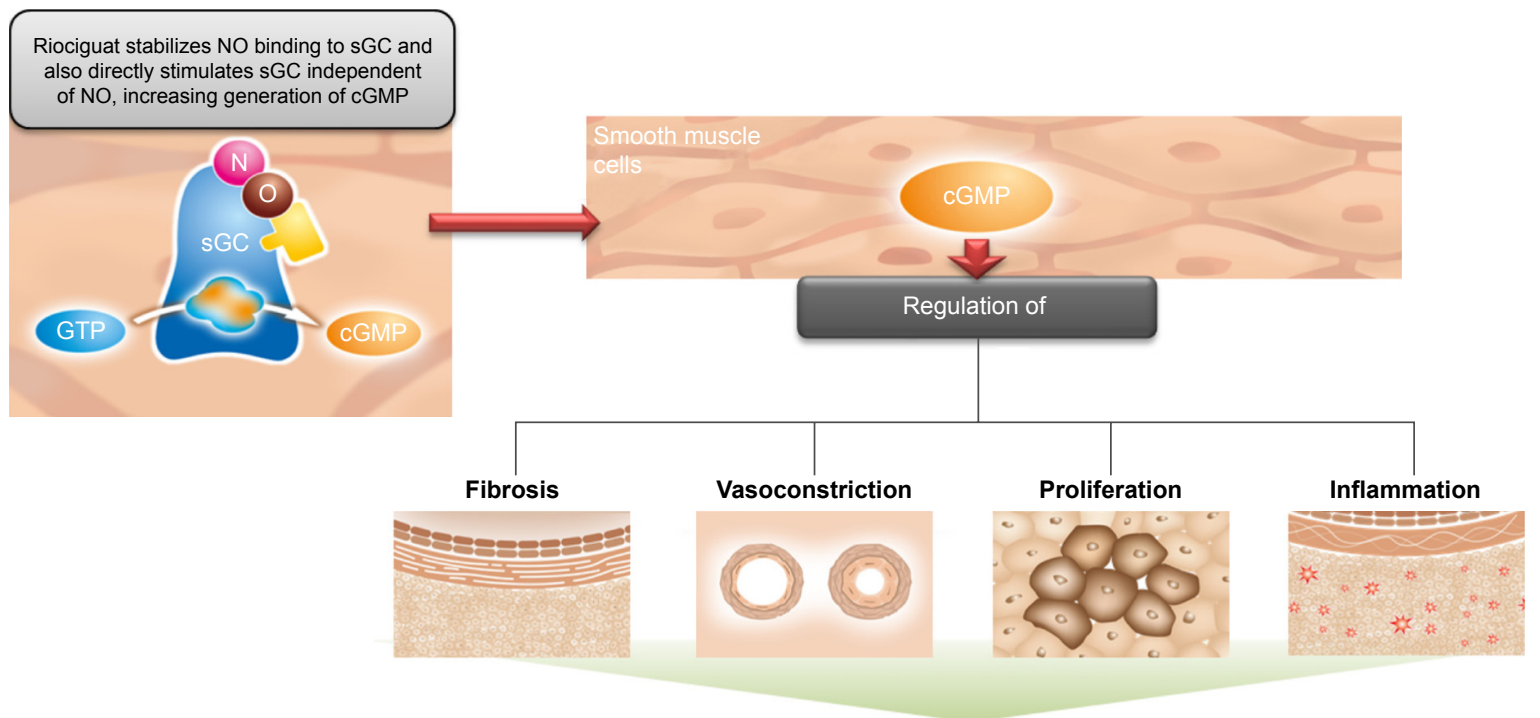

Figure 3 The dual mode of action of riociguat.

Notes: Reprinted from Chest, I5I (2), Ghofrani HA, Humbert M, Langleben D, et al, Riociguat: mode of action and clinical development in pulmonary hypertension, 468-480, Copyright (2017), with permission from Elsevier. ${ }^{26}$

Abbreviations: cGMP, cyclic guanosine monophosphate; GTP, guanosine triphosphate; NO, nitric oxide; sGC, soluble guanylate cyclase. 
foundation underlying reductions in urinary albumin excretion in diabetic endothelial NO knockout mice unresponsive to angiotensin receptor blockers, ${ }^{30}$ as well as cardiac and renal target-organ damage in both high- and low-renin hypertension rabbit models. ${ }^{31}$ Riociguat reduces infarct size and decreases the impact of infarction on left ventricular systolic function in mouse models of myocardial ischemia treated at the onset of reperfusion. ${ }^{32}$

\section{Pharmacokinetics of riociguat}

Riociguat has been evaluated in a series of pharmacokinetic (PK) studies. It is readily absorbed, with time to peak plasma concentrations of $0.5-1.5 \mathrm{~h}$ after dosing, and shows complete oral absorption, with no clinically meaningful differences when taken with or without food. ${ }^{33}$ Riociguat is mainly cleared by cytochrome P450 (CYP450) metabolism (CYP1A1, CYP3A4, and CYP2J2) via conversion to its main metabolite, $\mathrm{M} 1$, and has an elimination half-life of $\sim 12 \mathrm{~h}$ in patients with $\mathrm{PH} .^{33-37}$

No clinically meaningful increase in riociguat exposure has been demonstrated in patients with mild hepatic impairment, although moderate hepatic impairment (Child-Pugh Class B) was associated with increased riociguat exposure compared with sex-matched, healthy control subjects. ${ }^{38}$ No data are available in patients with severe hepatic impairment (Child-Pugh Class C). ${ }^{34,35}$

In patients with mild (creatinine clearance $[\mathrm{CrCl}]$ 80-50 $\mathrm{mL} / \mathrm{min})$, moderate $(\mathrm{CrCl}<50-30 \mathrm{~mL} / \mathrm{min})$, or severe $(\mathrm{CrCl}<30 \mathrm{~mL} / \mathrm{min})$ renal impairment, riociguat plasma concentrations were increased. ${ }^{35}$ Increased exposure associated with renal impairment was not accompanied by an increase in treatment-related adverse events (AEs). 7,39,40 Data are limited in patients with severe renal impairment, and no data are available in patients with $\mathrm{CrCl}<15 \mathrm{~mL} / \mathrm{min}$ or on dialysis..$^{34,35}$

There were no clinically meaningful effects of age, sex, weight, or race/ethnicity on the PK properties of riociguat in healthy volunteers. ${ }^{40,41}$ Smoking is known to induce CYP1A1, ${ }^{42}$ which has a major role in the metabolic clearance of riociguat, and plasma concentrations of riociguat are reduced by $50 \%-60 \%$ in smokers compared with nonsmokers. ${ }^{35}$

Based on its PK properties, the following recommendations for prescribing riociguat have been published:

- Caution should be exercised in prescribing riociguat to patients with moderate hepatic impairment, and riociguat should not be prescribed for patients with severe hepatic impairment. ${ }^{34,35}$
- Riociguat is not recommended in patients with $\mathrm{CrCl}<30 \mathrm{~mL} / \mathrm{min}$ in Europe and in patients with $\mathrm{CrCl}<15 \mathrm{~mL} / \mathrm{min}$ in the USA.

- Current smokers should be advised to stop smoking because of the risk of lower response, and a dose decrease may be required in patients who stop smoking during treatment. The recommended starting dose of riociguat is $1 \mathrm{mg}$ three times daily. For smokers, doses $>2.5 \mathrm{mg}$ three times daily may be considered to achieve similar exposure of riociguat to that observed in nonsmokers. The safety and effectiveness of riociguat doses $>2.5 \mathrm{mg}$ three times daily have not, however, been established..$^{34,35}$

Riociguat has no PK interactions with or effects on the exposure to endothelin receptor antagonists (ERAs) or non-intravenous prostanoids that merit dose adjustment. Although coadministration of bosentan reduces riociguat plasma concentrations, it is not necessary to adjust the dose of riociguat in patients receiving bosentan beyond the standard adjustment scheme according to systolic blood pressure (SBP), which should compensate for increased riociguat exposure. ${ }^{34,35}$ In the Phase III PATENT-1 trial, treatment-naïve patients and those receiving combination therapy with other PH-specific therapies benefited equally from riociguat treatment, and it was concluded that $2.5 \mathrm{mg}$ three times daily is the optimum riociguat dose for both patient groups. ${ }^{43-45}$ Owing to the potential to increase riociguat plasma concentrations, concomitant use with strong multipathway CYP and P-glycoprotein (P-gp)/breast cancer resistance protein inhibitors, such as azole antimycotics (eg, ketoconazole, itraconazole), or human immunodeficiency virus protease inhibitors (eg, ritonavir), is not recommended in the European summary of product characteristics. ${ }^{35}$ A starting dose of $0.5 \mathrm{mg}$ three times daily should be considered in these patients according to the US prescribing information. ${ }^{34}$

\section{Drug interactions}

In a double-blind, crossover, pharmacologic study in 30 healthy volunteers, no pharmacodynamic interactions were demonstrated between riociguat and warfarin. ${ }^{46}$ This is consistent with results from the PATENT-2 clinical trial, in which anticoagulation therapy was required by $61 \%$ of patients, with no evidence of interaction between riociguat and anticoagulants or increased risk of respiratory tract bleeding events. ${ }^{47}$ Several important drug-metabolizing enzymes have been tested in vitro for interactions with riociguat. The results suggested that riociguat is a $\mathrm{P}$-gp substrate, and so its efficacy may be increased when coadministered with strong 
P-gp inhibitors such as ketoconazole. ${ }^{48}$ Conversely, antacids and proton pump inhibitors may decrease riociguat exposure, but no dose adjustment is required for coadministration of proton pump inhibitors. ${ }^{49}$

\section{Clinical trials}

\section{Phase I and II studies}

Following Phase I dose-finding studies in healthy volunteers that showed that riociguat produced a mild reduction in BP and was well tolerated, ${ }^{33}$ the first Phase II trial was an acute hemodynamic study ${ }^{36}$ conducted in 19 patients with a diagnosis of PAH, distal CTEPH, or PH associated with mild-tomoderate interstitial lung disease (ILD). Incremental doses of riociguat were administered to four patients at hourly intervals until the mean arterial pressure was $<60 \mathrm{mmHg}$ or the heart rate increased to $>140 \mathrm{bpm}$. Riociguat dosing up to $2.5 \mathrm{mg}$ was generally well tolerated, but one patient had asymptomatic hypotension after a total dose of $5 \mathrm{mg}$. Another group of patients received a single dose of riociguat $1 \mathrm{mg}(\mathrm{n}=5)$ or riociguat $2.5 \mathrm{mg}(\mathrm{n}=10)$. The $\mathrm{PK}$ parameters of riociguat following single-dose administration are listed in Table 1. In both the $1 \mathrm{mg}$ and $2.5 \mathrm{mg}$ dose groups, riociguat achieved statistically significant reductions in mean pulmonary artery pressure (mPAP), PVR, SBP, and systemic vascular resistance (SVR) compared with baseline. An increase in cardiac index was also significant in both dose groups, although a significant increase in heart rate was observed only in the $2.5 \mathrm{mg}$ group. Furthermore, the improvement in hemodynamic parameters observed with riociguat was greater than that observed with inhaled NO. The extent of the hemodynamic effects caused by riociguat correlated significantly with riociguat plasma concentrations, which in turn were dose-dependent and showed interindividual variability. ${ }^{36}$

To evaluate the safety and tolerability and further explore the appropriate dosage of riociguat, a 12-week prospective, open-label, uncontrolled Phase II trial was initiated in patients with CTEPH who were not eligible for surgery $(n=42)$ or PAH $(n=33)$ and were treatment-naïve or receiving ERAs alone. ${ }^{39}$ Patients received riociguat immediate-release tablets three times daily for 12 weeks. The starting dose was $1 \mathrm{mg}$ and could be increased (according to peripheral SBP) by $0.5 \mathrm{mg}$ every 2 weeks up to the maximum dose of $2.5 \mathrm{mg}$ three times daily. In total, 41 patients with CTEPH and 31 with PAH completed the 12-week study. The maximum dose of riociguat $2.5 \mathrm{mg}$ three times daily was received by 52 patients $(72 \%)$ and was associated with only minor changes in SBP and heart rate. Exercise capacity was improved in $86 \%$ of patients during riociguat treatment; at 12 weeks, the median increase in 6-minute walking distance (6MWD) was $55 \mathrm{~m}$ (interquartile range, 20.0-107.0 m; $P<0.0001)$. The extent of the improvement was slightly less among patients in World Health Organization (WHO) functional class (FC) III than among those in WHO FC II at baseline, especially in the PAH subgroup. Patients taking riociguat with bosentan experienced similar improvements to those receiving riociguat alone. Among patients who underwent a second right heart catheterization after treatment with riociguat, a significant improvement was observed in hemodynamic parameters, including mPAP and mean PVR. These improvements were consistent with the increases in 6MWD observed in the majority of patients.

Phase II trials showed that riociguat was effective and well tolerated, and it was therefore entered into Phase III studies.

\section{CHEST-I and -2 Phase III study}

The CHEST-1 study was the pivotal Phase III clinical study that led to riociguat being approved for use in the treatment of inoperable or persistent/recurrent CTEPH. It was a multicenter, randomized, double-blind, placebo-controlled 16-week

Table I PK parameters of riociguat in plasma following single-dose administration of $2.5 \mathrm{mg}$ and I mg riociguat

\begin{tabular}{|c|c|c|c|c|c|c|}
\hline \multirow[t]{2}{*}{ Parameter } & \multicolumn{3}{|c|}{ Riociguat I mg (n=5) } & \multicolumn{3}{|c|}{ Riociguat $2.5 \mathrm{mg}(\mathrm{n}=10)$} \\
\hline & Geometric mean & CV\% & Range & Geometric mean & CV\% & Range \\
\hline AUC, $\mu g \cdot h / L$ & 602.3 & 14.9 & $456.5-749.6$ & I,4II & 39.2 & $597.5-3,121$ \\
\hline$C_{\max }, \mu g / L$ & 59.43 & 5.9 & $53.49-65.05$ & 119.4 & 16. I & $74.69-172.4$ \\
\hline$t_{\max }, h$ & $0.75^{\mathrm{a}}$ & & $0.500-1.500$ & $0.500^{\mathrm{a}}$ & & $0.250-1.500$ \\
\hline$t_{1 / 2}, h$ & 9.953 & 8.6 & $8.737-12.14$ & 11.65 & 38.6 & $4.680-28.58$ \\
\hline $\mathrm{Vz} / \mathrm{F}, \mathrm{L} / \mathrm{kg}$ & 0.354 & 73 & $0.307-0.393$ & 0.378 & 20.7 & $0.005-0.609$ \\
\hline $\mathrm{CL} / \mathrm{F}, \mathrm{L} / \mathrm{h}$ & 1.660 & 14.9 & $1.334-2.191$ & I.77| & 39.2 & $0.801-4.184$ \\
\hline
\end{tabular}

Notes: Subjects valid for PK and pharmacodynamic analysis. This material has not been reviewed prior to release; therefore the European Respiratory Society may not be responsible for any errors, omissions or inaccuracies, or for any consequences arising there from, in the content. Reproduced with permission of the European Respiratory Society (C. European Respiratory Journal. 2009;33(4):785-792. DOI: 10.1 183/09031936.00039808. ${ }^{36}$ aMedian.

Abbreviations: AUC, area under the plasma concentration-time curve; $C_{\max }$, maximum plasma concentration; $\mathrm{CL} / \mathrm{F}$, apparent total clearance of the drug from plasma; $\mathrm{CV}$, coefficient of variation; $\mathrm{PK}$, pharmacokinetic; $\mathrm{t}_{\max }$, time to reach $C_{\max } ; \mathrm{t}_{1 / 2}$, terminal half-life; $\mathrm{Vz} / \mathrm{F}$, apparent volume of distribution during the terminal phase. 
study that was conducted in 26 countries in 261 patients with inoperable CTEPH or persistent/recurrent CTEPH after PEA. ${ }^{7}$ Eligible patients were aged between 18 and 80 years and had a 6MWD of 150-450 m, PVR >300 dyn $\cdot \mathrm{s} \cdot \mathrm{cm}^{-5}$, and $\mathrm{mPAP} \geq 25 \mathrm{mmHg}$. Eligible patients could not receive ERAs, PDE5 inhibitors, prostanoids, or NO donors within 3 months before entering the study. Patients enrolled in the study were randomly assigned in a 1:2 ratio to receive placebo or riociguat $0.5-2.5 \mathrm{mg}$ three times daily, individually doseadjusted according to SBP. The primary end point was change from baseline in 6MWD at Week 16; secondary efficacy end points included changes in PVR, $N$-terminal pro-brain natriuretic peptide (NT-proBNP) level, WHO FC, time to clinical worsening, and quality of life variables.

The primary end point was met, with mean 6MWD at Week 16 increasing by $39 \mathrm{~m}$ in the riociguat group compared with a decrease of $6 \mathrm{~m}$ in the placebo group (Figure 4). Riociguat also improved several hemodynamic end points, including PVR and WHO FC, and reduced NT-proBNP (Table 2). Patients with inoperable CTEPH and postPEA CTEPH showed comparable responses to riociguat treatment.
Patients who completed CHEST-1 without ongoing drugrelated serious AEs (SAEs) were eligible to participate in the open-label extension study, CHEST-2, which assessed the long-term efficacy and safety of riociguat. ${ }^{50}$ CHEST-2 enrolled 237 patients, all of whom received riociguat up to $2.5 \mathrm{mg}$ three times daily. In contrast to CHEST-1, patients could receive concomitant ERAs and prostanoids. In an interim analysis, with a March 2013 data cutoff, the mean treatment duration was 83 weeks and 179 patients had been treated with riociguat for over 1 year.

Compared with baseline values, the results of CHEST-2 at 1 year showed a 51-m increase in 6MWD, improvement in WHO FC in $47 \%$ of patients, and a reduction in NT-proBNP levels. ${ }^{50}$ The estimated rate of clinical worsening-free survival was $88 \%$, and the estimated overall survival rate at 1 year was $97 \%$.

In a final analysis of CHEST-2 conducted at the March 2014 data cutoff, 172 patients were ongoing, 171 had received $\geq 2$ years of treatment, and 18 patients had switched to the commercial drug. ${ }^{51}$ At 2 years, the improvement in 6MWD was maintained, FC had improved in 39\% of patients, and the estimated survival was 93\%.6MWD improved in

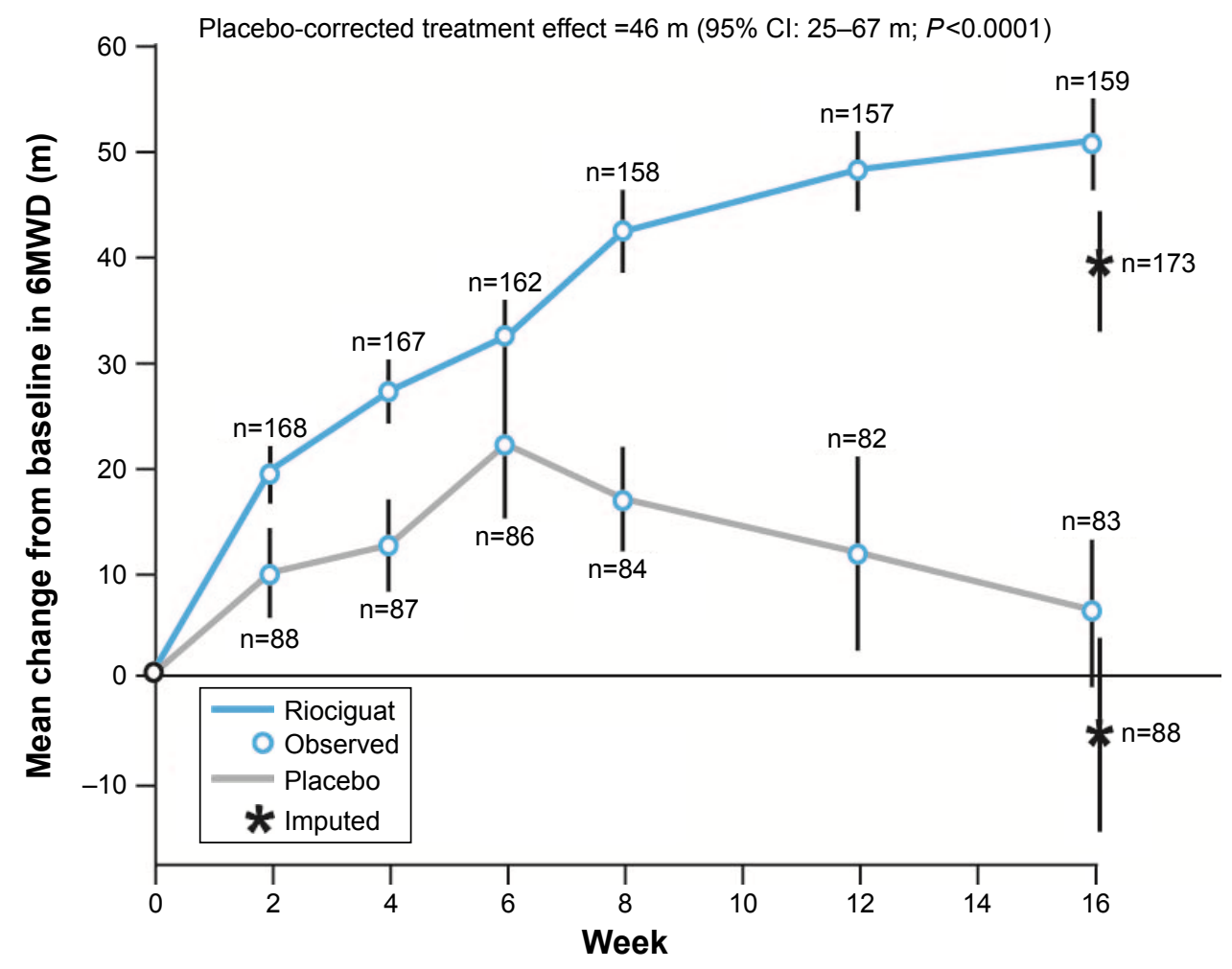

Figure 4 Mean change in 6MWD in the CHEST-I study.

Notes: Last visit - last observed value (not including follow-up) for patients who completed the study or withdrew, except imputed worst value (0) in case of death or clinical worsening without a termination visit or a measurement at that termination visit. From N Engl J Med, Ghofrani HA, D'Armini AM, Grimminger F, et al; CHEST-I Study Group, Riociguat for the treatment of chronic thromboembolic pulmonary hypertension. 369(4):319-329.7 Copyright @ 2013 Massachusetts Medical Society. Reprinted with permission from the Massachusetts Medical Society.

Abbreviations: 6MWD, 6-minute walking distance; $\mathrm{Cl}$, confidence interval. 
Table 2 Changes in selected parameters in the CHEST-I study

\begin{tabular}{|c|c|c|c|c|c|c|}
\hline \multirow[t]{2}{*}{ Parameter } & \multicolumn{2}{|l|}{ Riociguat } & \multicolumn{2}{|l|}{ Placebo } & \multirow{2}{*}{$\begin{array}{l}\text { Placebo- } \\
\text { corrected LS } \\
\text { mean difference }\end{array}$} & \multirow{2}{*}{$\begin{array}{l}P \text {-value, } \\
\text { riociguat } \\
\text { vs placebo }\end{array}$} \\
\hline & Baseline & $\begin{array}{l}\text { Mean change } \\
\text { from baseline }\end{array}$ & Baseline & $\begin{array}{l}\text { Mean change } \\
\text { from baseline }\end{array}$ & & \\
\hline PVR, dyn $\cdot s \cdot \mathrm{cm}^{-5}$ & 791 & -226 & 779 & +23 & -246 & $<0.001$ \\
\hline mPAP, mmHg & 45 & -4 & 44 & +0.8 & -4 & $<0.001$ \\
\hline $\mathrm{CO}, \mathrm{L} / \mathrm{min}$ & 4 & +0.8 & 4 & -0.03 & +0.9 & $<0.001$ \\
\hline NT-proBNP, ng/L & $\mathrm{I}, 508$ & -291 & $\mathrm{I}, 706$ & +76 & -444 & $<0.001$ \\
\hline \multicolumn{7}{|l|}{ WHO FCa } \\
\hline I/II/III/IV (\%) & $2 / 32 / 62 / 5$ & - & $0 / 29 / 69 / 2$ & - & - & \\
\hline Improved/unchanged/worsened (\%) & - & $33 / 62 / 5$ & - & 15/78/7 & - & 0.003 \\
\hline Borg dyspnea score & 4 & -0.8 & 4 & +0.2 & - & 0.004 \\
\hline
\end{tabular}

Notes: Baseline values are mean values. From N Engl J Med, Ghofrani HA, D’Armini AM, Grimminger F, et al; CHEST-I Study Group, Riociguat for the treatment of chronic thromboembolic pulmonary hypertension, 369(4):319-329.' Copyright (C) (2013) Massachusetts Medical Society. Reprinted with permission from the Massachusetts Medical Society. ${ }^{2} \mathrm{WHO}$ FC data show percentages of patients in class I/II/III/IV and baseline, and percentages improved/unchanged/worsened at the end of Week I6.

Abbreviations: CO, cardiac output; FC, functional class; LS, least squares; mPAP, mean pulmonary artery pressure; NT-proBNP, N-terminal pro-brain natriuretic peptide; PVR, pulmonary vascular resistance; WHO, World Health Organization.

patients who had received riociguat in CHEST-1 and those originally randomized to placebo, although the increase was greater in the former riociguat group. Quality of life measured by EuroQol-5 Dimension (EQ-5D) questionnaire score was improved. ${ }^{52}$

Taken together, results from CHEST-1 and -2 indicate that riociguat significantly improves exercise capacity, other clinical outcomes, and hemodynamics in patients with inoperable CTEPH or persistent/recurrent CTEPH and that long-term treatment is associated with sustained clinical benefits and good long-term survival. The effects on hemodynamic values, which have been shown in other studies to predict outcomes, were considered clinically significant, while $\mathrm{WHO} F C$, as well as indicating a patient's perception of treatment benefit, correlates with survival among patients with CTEPH..$^{53}$ Although comparisons between clinical trials should be made with caution, the CHEST-1 and -2 results were promising compared with those of the BENEFIT trial, in which bosentan decreased PVR compared with placebo in patients with CTEPH but did not significantly increase 6MWD. ${ }^{54}$ The observation in CHEST-2 that the former placebo group did not fully "catch up" in 6MWD with the former riociguat group indicates the importance of starting treatment early.

\section{PATENT-I and -2 Phase III study}

Approval of riociguat for the treatment of $\mathrm{PAH}$ was based on data from the pivotal Phase III PATENT-1 study, a 12-week, double-blind, randomized, placebo-controlled trial in 443 patients with symptomatic PAH (PVR $>300$ dyn $\cdot \mathrm{s} \cdot \mathrm{cm}^{-5}$, $\mathrm{mPAP} \geq 25 \mathrm{mmHg}, 6 \mathrm{MWD} 150-450 \mathrm{~m}) .{ }^{45}$ Patients were eligible for the study if they were treatment-naïve or receiving ERAs or prostanoids (except for intravenous prostanoids) at stable doses for 90 days before study entry. Patients were randomly assigned in a 2:4:1 ratio to receive placebo, riociguat individually dose adjusted up to $2.5 \mathrm{mg}$ three times

Table 3 Changes in selected parameters in the PATENT-I study

\begin{tabular}{|c|c|c|c|c|c|c|}
\hline \multirow[t]{2}{*}{ Parameter } & \multicolumn{2}{|l|}{ Riociguat } & \multicolumn{2}{|l|}{ Placebo } & \multirow{2}{*}{$\begin{array}{l}\text { Placebo- } \\
\text { corrected LS } \\
\text { mean difference }\end{array}$} & \multirow{2}{*}{$\begin{array}{l}\text { P-value, } \\
\text { riociguat } \\
\text { vs placebo }\end{array}$} \\
\hline & Baseline & $\begin{array}{l}\text { Mean change } \\
\text { from baseline }\end{array}$ & Baseline & $\begin{array}{l}\text { Mean change } \\
\text { from baseline }\end{array}$ & & \\
\hline PVR, dyn.s.cm ${ }^{-5}$ & 791 & -223 & 834 & -9 & -226 & $<0.001$ \\
\hline $\mathrm{mPAP}, \mathrm{mmHg}$ & 47 & -4 & 49 & -0.5 & -4 & $<0.001$ \\
\hline $\mathrm{CO}, \mathrm{L} / \mathrm{min}$ & 4 & +1 & 4 & -0.01 & +0.9 & $<0.001$ \\
\hline NT-proBNP, ng/L & $\mathrm{I}, 027$ & -198 & $\mathrm{I}, 228$ & +232 & -432 & $<0.001$ \\
\hline \multicolumn{7}{|l|}{ WHO FC } \\
\hline I/II/III/IV (\%) & $2 / 43 / 55 / 0.4$ & - & $3 / 48 / 46 / 2$ & - & - & \\
\hline Improved/unchanged/worsened (\%) & - & $21 / 76 / 4$ & - & $|4 / 7| / \mid 4$ & - & 0.003 \\
\hline Borg dyspnea score & 4 & -0.4 & 3.9 & +0.1 & - & 0.002 \\
\hline
\end{tabular}

Notes: Baseline values are mean values. From N Engl J Med, Ghofrani HA, Galiè N, Grimminger F, et al, Riociguat for the treatment of pulmonary arterial hypertension,

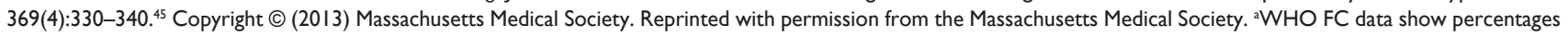
of patients in class I/II/III/IV and baseline, and percentages improved/unchanged/worsened at the end of Week 12.

Abbreviations: $\mathrm{CO}$, cardiac output; FC, functional class; LS, least squares; mPAP, mean pulmonary artery pressure; NT-proBNP, N-terminal pro-brain natriuretic peptide; PVR, pulmonary vascular resistance; WHO, World Health Organization. 
daily, or riociguat $1.5 \mathrm{mg}$ three times daily. The primary end point was the change from baseline in 6MWD at Week 12. Secondary end points included changes from baseline to Week 12 in PVR, NT-proBNP levels, WHO FC, time to clinical worsening, Borg dyspnea scale score, and quality of life questionnaire scores.

The primary end point was met at Week 12; mean 6MWD increased from baseline by $30 \mathrm{~m}$ in the riociguat $2.5 \mathrm{mg}$ maximum group compared with a decrease of $6 \mathrm{~m}$ with placebo (Table 3). ${ }^{45}$ Riociguat also improved several hemodynamic end points, WHO FC, and Borg dyspnea score and reduced NT-proBNP (Table 3). Improvements were seen in both treatment-naïve patients and those pretreated with ERAs or non-intravenous prostanoids. ${ }^{43-45}$ Furthermore, riociguat increased the proportions of patients with $\mathrm{PAH}$ achieving predefined treatment goals known to correlate with improved outcomes, including clinically relevant thresholds for 6MWD, WHO FC, NT-proBNP levels, and hemodynamic parameters, ${ }^{55}$ illustrating the homogeneity of response to riociguat across a range of different parameters. There was also a significantly lower incidence of events indicating clinical worsening in the 2.5 mg-maximum group than in the placebo group. ${ }^{45}$

Patients completing PATENT-1 without ongoing drugrelated SAEs were eligible to participate in the open-label, single-group, multicenter, PATENT-2 extension study. ${ }^{47}$ In total, 396 patients enrolled in PATENT-2; 84\% had received treatment for at least 1 year at the March 2013 data cutoff. The mean treatment duration was 95 weeks.

At 1 year, the mean 6MWD had increased by $51 \mathrm{~m}$ (Figure 5, which also shows the changes in 6MWD in
PATENT-1), WHO FC had improved in $33 \%$ of patients, and the decreases in NT-proBNP observed in PATENT-1 sustained. ${ }^{47}$ At 1 year, the estimated rates of clinical worsening-free survival and overall survival were $88 \%$ and $97 \%$, respectively. ${ }^{47}$

After 2 years of PATENT-2, 275 patients were ongoing, 307 had received $\geq 2$ years of treatment, and 13 patients had switched to the commercial drug. ${ }^{56,57}$ At 2 years, improvements in 6MWD were maintained, and the estimated survival was $93 \%$.

The results from PATENT-1 and -2 show that riociguat significantly improves exercise capacity and several other secondary end points in patients with symptomatic PAH and that long-term treatment is associated with sustained clinical improvements. The increase in 6MWD with riociguat compared with placebo was within the range seen in trials of other medical therapies for $\mathrm{PAH}^{58-63}$ or considered clinically relevant in other studies. ${ }^{64-66}$ Delay of clinical worsening, as observed with riociguat in PATENT-1, is also considered clinically relevant. ${ }^{67}$ The long-term changes in 6MWD with riociguat in PATENT-2 were also in a similar range to those of long-term studies of other PAH therapies. ${ }^{68-70}$

\section{PATENT PLUS}

It had been hypothesized that concomitant use of riociguat with a PDE5 inhibitor may have additional benefit, as the two drugs target the same pathway via different mechanisms. This combination was evaluated in the randomized, doubleblind PATENT PLUS study. ${ }^{56}$ Patients aged $18-75$ years with symptomatic PAH receiving stable ( $\geq 90$ days) sildenafil therapy (20 $\mathrm{mg}$ three times daily) were eligible for the

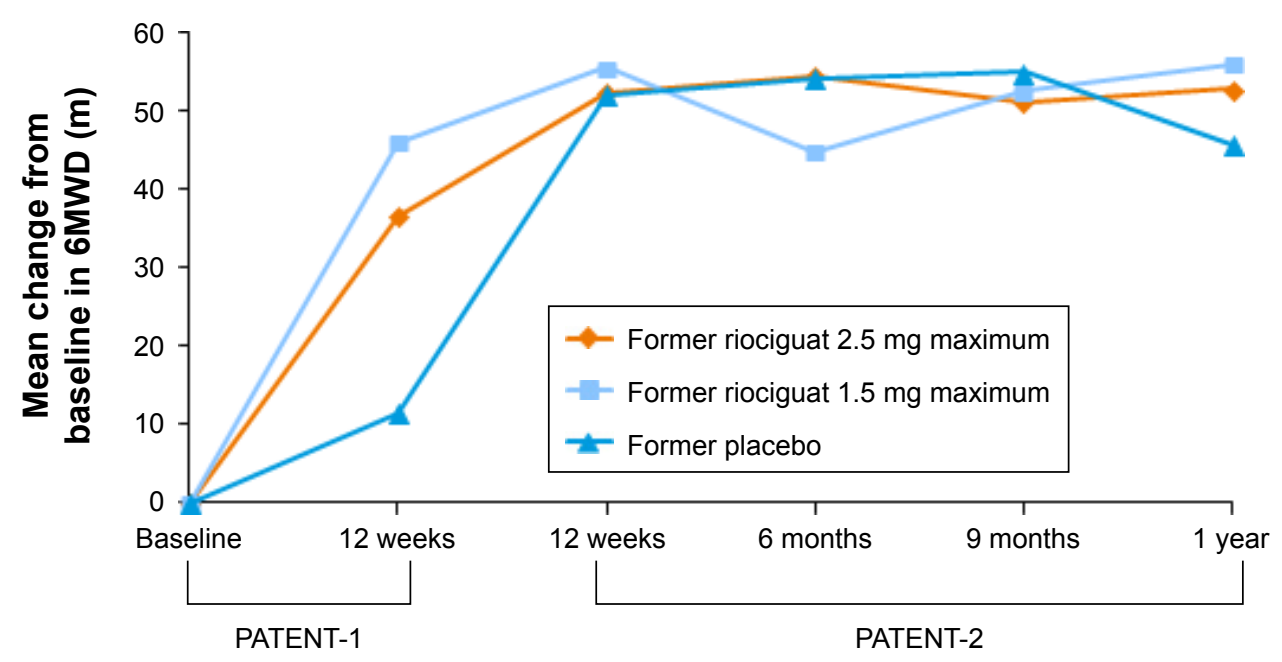

Figure 5 Change from baseline in 6MWD in PATENT-I and PATENT-2.

Notes: Note that "I 2 weeks" in PATENT-2 represents 24 weeks of treatment: treatment was continuous from PATENT-I to PATENT-2. Reproduced with permission of the European Respiratory Society (C): European Respiratory Journal. 2015;45(5): 1303-|3 I3. DOI: 10.1 I83/0903 I936.000906 I4. ${ }^{47}$

Abbreviation: 6MWD, 6-minute walking distance. 
study. The patients were randomized to receive riociguat (individually adjusted up to $2.5 \mathrm{mg}$ three times daily: $\mathrm{n}=12$ ) or placebo $(n=6)$ for a total treatment duration of 12 weeks. ${ }^{56}$ The primary outcome was the maximum change in supine SBP from baseline within $4 \mathrm{~h}$ of dosing. There was no significant difference between the riociguat and placebo groups in the primary end point, other hemodynamic parameters, or exercise capacity. Combination therapy was found to be associated with a higher rate of discontinuation due to hypotension, possibly because both riociguat and PDE5 inhibitors were administered systemically, and not selectively to the pulmonary bed, therefore impacting systemic circulation. ${ }^{56}$ As a result of these observations, use of riociguat in patients receiving PDE5 inhibitors is contraindicated. ${ }^{34}$

\section{Clinical trials of riociguat in other types of $\mathrm{PH}$}

A Phase IIb double-blind, randomized, placebo-controlled, dose-ranging hemodynamic study of riociguat was conducted in patients with $\mathrm{PH}$ associated with systolic left ventricular dysfunction (LEPHT). ${ }^{71}$ Patients with HF with left ventricular ejection fraction $\leq 40 \%$ and $\mathrm{mPAP} \geq 25 \mathrm{mmHg}$ were eligible for enrollment if standard therapy for 30 days had not ameliorated symptoms. In total, 201 patients were randomized in a $2: 1: 1: 2$ ratio to receive riociguat $0.5 \mathrm{mg}, 1.0 \mathrm{mg}$, or $2.0 \mathrm{mg}$ three times daily or placebo. The efficacy end points were placebo-corrected changes from baseline in right heart hemodynamic parameters after 16 weeks of treatment. Statistically significant improvements were achieved for PVR, SVR, cardiac index, and stroke volume index, without changes in heart rate or SBP, in patients receiving riociguat $2 \mathrm{mg}$ vs those receiving placebo. By contrast, the changes in mPAP, PCWP, or transpulmonary gradient did not differ significantly between the riociguat and placebo groups. In keeping with the known dose-dependent relationship between riociguat and changes in hemodynamics, no statistically different changes were observed with the lower doses of riociguat $(0.5 \mathrm{mg}$ and $1.0 \mathrm{mg})$ compared with placebo. There were no significant differences in echocardiography parameters or clinical variables (such as New York Heart Association classification and clinical worsening) between the riociguat $2.0 \mathrm{mg}$ and placebo groups. However, riociguat significantly reduced the Minnesota Living with Heart Failure score. $^{71}$

DILATE-1, a Phase IIa randomized, double-blind, placebo-controlled, single-dose clinical study, investigated riociguat as a treatment for $\mathrm{PH}$ associated with diastolic HF. ${ }^{72}$ The 39 patients enrolled were randomized to receive placebo $(n=13)$ or riociguat $0.5 \mathrm{mg}(\mathrm{n}=8), 1.0 \mathrm{mg}(\mathrm{n}=8)$, or $2.0 \mathrm{mg}(\mathrm{n}=8)$ as single doses. No significant differences were observed between the riociguat $2.0 \mathrm{mg}$ and placebo groups in peak decrease in MPAP (the primary efficacy variable), pulmonary arterial wedge pressure (PAWP), or PVR. However, stroke volume and cardiac index were significantly increased, without significantly changing the heart rate. Riociguat $2.0 \mathrm{mg}$ also significantly improved right ventricular end-diastolic area and left atrial area, as determined by echocardiography, compared with placebo. ${ }^{72}$

Riociguat has also been investigated in $\mathrm{PH}$ associated with ILD (PH-ILD). Riociguat has also been investigated in PH associated with ILD (PH-ILD) in an initial open-label, uncontrolled pilot study in 22 patients. ${ }^{73}$ The results were disappointing, only 18 patients completed the 12-week trial; there were four withdrawals due to AEs, of which two were considered to be drug related. Of the 15 patients who participated in the long-term extension phase, six withdrew from the study; the reasons for discontinuing therapy included death, lung transplantation, and intolerable AEs. Furthermore, there was only a small increase in 6MWD and no change in mPAP. ${ }^{73}$ It has been suggested that the slight decrease in oxygenation and increase in cardiac output may be a consequence of increased shunting and ventilation-perfusion mismatch. ${ }^{74}$ Subsequently, riociguat was investigated in the RISE-IIP study (ClinicalTrials.gov: NCT02138825) in patients with idiopathic interstitial pneumonia (IIP), a distinct category of ILD. ${ }^{75}$ Patients with IIP were randomized double blind in a $1: 1$ ratio to receive riociguat adjusted to a maximum of $2.5 \mathrm{mg}$ three times daily or sham-adjusted placebo in a 10-week dose-adjustment phase, followed by a 16-week maintenance phase with 6MWD as the primary end point. An open-label extension phase was also planned. This study was terminated prematurely on the advice of the safety committee because of possible increases in mortality and $\mathrm{AE}$ rates in the riociguat arm. ${ }^{76} \mathrm{PH}$ associated with IIP is now a contraindication to riociguat. ${ }^{77}$

\section{Safety}

Riociguat is generally well tolerated and has a similar good safety profile in patients with CTEPH and in patients with treatment-naïve or pretreated $\mathrm{PAH}$, $^{7,45,47,50,51,57}$ Most AEs are related to the mechanism of action of riociguat ${ }^{34}$ and are of mild-to-moderate intensity., ${ }^{7,45}$ In a pooled analysis of the PATENT-1 and CHEST-1 studies, AEs occurring more frequently with riociguat vs placebo included headache $(27 \%$ vs $18 \%$, respectively), dyspepsia/gastritis (21\% vs $8 \%$ ), dizziness ( $20 \%$ vs $13 \%$ ), nausea (14\% vs $11 \%$ ), diarrhea (12\% vs $8 \%$ ), 
Table 4 Incidences of most common AEs with riociguat therapy in the CHEST $-2^{51}$ and PATENT $-2^{57}$ studies

\begin{tabular}{|c|c|c|}
\hline AE, n (\%) & $\begin{array}{l}\text { CHEST-2 } \\
(n=237)\end{array}$ & $\begin{array}{l}\text { PATENT-2 } \\
(\mathrm{n}=396)\end{array}$ \\
\hline Any AE & $233(98)$ & $388(98)$ \\
\hline \multicolumn{3}{|l|}{$A E s$ in $\geq 15 \%$ of patients in either study } \\
\hline Nasopharyngitis & $67(28)$ & $118(30)$ \\
\hline Peripheral edema & $55(23)$ & $98(25)$ \\
\hline Dizziness & $52(22)$ & $10 \mid(26)$ \\
\hline Diarrhea & $43(18)$ & $84(21)$ \\
\hline Cough & $37(16)$ & $88(22)$ \\
\hline Headache & $35(15)^{a}$ & $82(21)$ \\
\hline Dyspnea & $35(15)^{\mathrm{a}}$ & $64(16)$ \\
\hline Upper respiratory tract infection & $33(14)^{a}$ & $64(16)$ \\
\hline Nausea & $30(13)^{a}$ & $76(19)$ \\
\hline Dyspepsia & $26(11)^{a}$ & $54(14)^{a}$ \\
\hline Vomiting & $20(8)^{\mathrm{a}}$ & $67(17)$ \\
\hline \multicolumn{3}{|c|}{ AEs of special interest in $>5 \%$ of patients in either study } \\
\hline Syncope & $23(10)$ & $38(10)$ \\
\hline Hypotension ${ }^{\mathrm{b}}$ & $18(8)$ & $51(13)$ \\
\hline \multicolumn{3}{|l|}{ Other AEs of interest } \\
\hline Hemoptysis/pulmonary hemorrhage & $13(5)$ & $30(8)$ \\
\hline Drug-related AEs & $114(48)$ & $232(59)$ \\
\hline Serious AEs & $129(54)$ & $238(60)$ \\
\hline Syncope & $23(10)$ & $38(10)$ \\
\hline Hemoptysis/pulmonary hemorrhage & $4(2)$ & $13(3)$ \\
\hline Discontinuation due to $\mathrm{AE}$ & $14(6)$ & $45(11)$ \\
\hline
\end{tabular}

Notes: aBayer AG, data on file. budged by the investigator based on patient symptoms. Abbreviation: $\mathrm{AE}$, adverse event.

hypotension ( $10 \%$ vs $4 \%$ ), and vomiting (10\% vs $7 \%){ }^{34}$ Syncope and right heart failure were the most commonly reported $\mathrm{SAE}$ in both riociguat- and placebo-treated groups in the PATENT-1 and CHEST-1 studies. ${ }^{7,45}$ SAEs of bleeding occurred more frequently with riociguat than placebo, including five patients (1\%) with SAEs of hemoptysis, one of which was fatal. ${ }^{34}$ The overall rates of discontinuation due to an $\mathrm{AE}$ were $2.9 \%$ for riociguat and $5.1 \%$ for placebo. ${ }^{34}$ The long-term safety profile of riociguat in the extension studies was similar to that observed in the PATENT-1 and CHEST-1 studies, with no new safety signals identified (Table 4). ${ }^{47,50}$

\section{Discussion}

The results of the PATENT and CHEST studies showed that patients with PAH or inoperable or persistent/recurrent CTEPH on long-term riociguat treatment have sustained improvements in clinical and functional status. As a result, riociguat is currently the only medication approved for the treatment of both PAH and CTEPH and is the only pharmacologic therapy approved for the treatment of inoperable or persistent/recurrent CTEPH following PEA. In addition, riociguat is the only drug to show consistent improvement in 6MWD in randomized, double-blind, placebo-controlled clinical trials in this condition. Furthermore, riociguat appears to have acceptable tolerability and side-effect profiles.

Hemoptysis and pulmonary hemorrhage are recognized complications of PH, particularly in CTEPH and in those taking anticoagulation therapy. ${ }^{1,35}$ Riociguat may potentially increase this risk of bleeding, especially in the presence of risk factors, such as recent episodes of serious hemoptysis. ${ }^{35}$ These observations suggest that the risk of pulmonary hemorrhage does not increase with the duration of riociguat exposure. Nonetheless, riociguat should be avoided in patients with a history of serious hemoptysis and those who have previously undergone bronchial arterial embolization. ${ }^{35}$

PAH and CTEPH are characterized by remodeling of the pulmonary vasculature leading to increased PVR. Changes in NO-sGC-cGMP signaling have been implicated in these processes. ${ }^{11,12,78}$ Several ex vivo and in vivo studies indicate that riociguat has pulmonary vasodilatory and anti-remodeling properties. ${ }^{12}$ The results seen with riociguat in $\mathrm{PAH}$ and CTEPH support the contention that the NO-sGC-cGMP pathway is involved in the pathophysiology of these disorders. As described earlier, riociguat appears to have a greater effect than other medical therapies on 6MWD in CTEPH, whereas its effect in PAH is similar to other drugs. These observations suggest different pathologies in the two conditions and possibly a more significant role for the NO-sGC-cGMP pathway in CTEPH.

Given that YC-1 - the prototype molecule of riociguat inhibits hypoxia-inducible factor-1 (HIF-1) and that HIF-1 has been proven to participate in the progression of pulmonary vessel wall remodeling, ${ }^{79}$ it seems reasonable to hypothesize that riociguat may negatively affect HIF-1 signaling, thereby inhibiting the cell proliferation and apoptosis resistance involved in remodeling of the pulmonary vessel wall. It may be expected that riociguat could have long-term efficacy effects related to potential reversal of pathologic changes in the pulmonary artery, although further confirmatory studies are needed.

Studies of BAY 60-4554, the main metabolite of riociguat that also has sGC stimulating activity, in 42 patients with biventricular HF demonstrated improvements in biventricular preload and afterload, as well as cardiac index, indicating a potential benefit with riociguat in the treatment of LEPHT. ${ }^{80}$ However, in clinical trials of patients with $\mathrm{PH}$ associated with systolic ventricular dysfunction or diastolic $\mathrm{HF}$, riociguat has shown minimal efficacy. ${ }^{71,72}$ As there is a huge gulf between preclinical research and clinical trials, further studies should 
be undertaken to investigate undefined pathophysiological mechanisms in LEPHT.

Additional preclinical studies have demonstrated that riociguat has beneficial effects on other pathologic processes implicated in $\mathrm{PH}$, including antifibrotic, antiproliferative, and anti-inflammatory effects, ${ }^{27-29,31,81}$ and it has recently been shown to have positive effects on experimental skin fibrosis. ${ }^{82}$ These findings suggested a potential role for riociguat in the treatment of systemic sclerosis, a rare, autoimmune rheumatic disease characterized by progressive fibrosis of the skin and internal organs. ${ }^{83,84} \mathrm{~A}$ randomized, double-blind, 52-week study is ongoing comparing riociguat with placebo in $\sim 130$ patients with diffuse cutaneous systemic sclerosis (ClinicalTrials.gov: NCT02283762).

\section{Conclusion}

Riociguat is an sGC stimulator that increases cGMP levels through a dual mode of action (direct stimulation of sGC, independent of $\mathrm{NO}$, and stabilization of $\mathrm{NO}-\mathrm{sGC}$ binding). It significantly improves exercise capacity and hemodynamic parameters in patients with PAH (irrespective of whether they are treatment naïve or pretreated) and in patients with CTEPH that is not suitable for surgery or persists after surgery (although patients at increased risk of bleeding should be evaluated with care).

The efficacy of riociguat in the treatment of $\mathrm{PAH}$ is comparable to PAH-specific drugs currently used in clinical practice. Riociguat appears to be an exciting new targeted medication for PAH. Its significant efficacy in treating CTEPH is invaluable, and its potential influence on pathologic mechanisms is desirable.

\section{Acknowledgment}

Medical writing support for this review was provided by Adelphi Communications, the UK, and was funded by Bayer AG.

\section{Disclosure}

Zhi-Cheng Jing reports receiving personal fees from Bayer AG, Actelion, Pfizer, and United Therapeutics.

Tian-Yu Lian and Xin Jiang have no conflicts of interest to report in this work.

\section{References}

1. Galie N, Humbert M, Vachiery JL, et al. 2015 ESC/ERS Guidelines for the diagnosis and treatment of pulmonary hypertension: The Joint Task Force for the Diagnosis and Treatment of Pulmonary Hypertension of the European Society of Cardiology (ESC) and the European Respiratory Society (ERS): Endorsed by: Association for European Pediatric and Congenital Cardiology (AEPC), International Society for Heart and Lung Transplantation (ISHLT). Eur Respir J. 2015;46(4):903-975.
2. Schermuly RT, Janssen W, Weissmann N, Stasch JP, Grimminger F, Ghofrani HA. Riociguat for the treatment of pulmonary hypertension. Expert Opin Investig Drugs. 2011;20(4):567-576.

3. Taichman DB, Ornelas J, Chung L, et al. Pharmacological therapy for pulmonary arterial hypertension in adults: CHEST guideline and expert panel report. Chest. 2014;146:449-475.

4. D'Alonzo GE, Barst RJ, Ayres SM, et al. Survival in patients with primary pulmonary hypertension. Results from a national prospective registry. Ann Intern Med. 1991;115(5):343-349.

5. Taichman DB, Shin J, Hud L, et al. Health-related quality of life in patients with pulmonary arterial hypertension. Respir Res. 2005;6:92.

6. Lang IM. Managing chronic thromboembolic pulmonary hypertension: pharmacological treatment options. Eur Respir Rev. 2009;111(18): 24-28.

7. Ghofrani HA, D'Armini AM, Grimminger F, et al; CHEST-1 Study Group. Riociguat for the treatment of chronic thromboembolic pulmonary hypertension. $N$ Engl J Med. 2013;369(4):319-329.

8. Pepke-Zaba J, Delcroix M, Lang I, et al. Chronic thromboembolic pulmonary hypertension (CTEPH): results from an International Prospective Registry. Circulation. 2011;124(18):1973-1981.

9. Pepke-Zaba J, Jansa P, Kim NH, Naejie R, Simonneau G. Chronic thromboembolic pulmonary hypertension: role of medical therapy. Eur Respir J. 2013;41(4):985-990.

10. Klinger JR, Abman SH, Gladwin MT. Nitric oxide deficiency and endothelial dysfunction in pulmonary arterial hypertension. Am J Respir Crit Care Med. 2013;188(6):639-646.

11. Stasch JP, Pacher P, Evgenov OV. Soluble guanylate cyclase as an emerging therapeutic target in cardiopulmonary disease. Circulation. 2011;123(20):2263-2273.

12. Stasch JP, Evgenov OV. Soluble guanylate cyclase stimulators in pulmonary hypertension. Handb Exp Pharmacol. 2013;218:279-313.

13. Pullamsetti S, Kiss L, Ghofrani HA, et al. Increased levels and reduced catabolism of asymmetric and symmetric dimethylarginines in pulmonary hypertension. FASEB J. 2005;19(9):1175-1177.

14. Cerra MC, Pellegrino D. Cardiovascular cGMP-generating systems in physiological and pathological conditions. Curr Med Chem. 2007; 14(5):585-599.

15. Budworth J, Meillerais S, Charles I, Powell K. Tissue distribution of the human soluble guanylate cyclases. Biochem Biophys Res Commun. 1999;263(3):696-701.

16. Mergia E, Friebe A, Dangel O, Russwurm M, Koesling D. Spare guanylyl cyclase NO receptors ensure high NO sensitivity in the vascular system. J Clin Invest. 2006;116(6):1731-1737.

17. Vermeersch P, Buys E, Pokreisz P, et al. Soluble guanylate cyclasealphal deficiency selectively inhibits the pulmonary vasodilator response to nitric oxide and increases the pulmonary vascular remodeling response to chronic hypoxia. Circulation. 2007;116(8):936-943.

18. Nimmegeers S, Sips P, Buys E, Decaluwe K, Brouckaert P, Van de Voorde J. Role of the soluble guanylyl cyclase alpha1-subunit in mice corpus cavernosum smooth muscle relaxation. Int J Impot Res. 2008; 20(3):278-284.

19. Baskaran P, Heckler EJ, van den Akker F, Beuve A. Identification of residues in the heme domain of soluble guanylyl cyclase that are important for basal and stimulated catalytic activity. PLoS One. 2011;6(11):e26976.

20. Friebe A, Wedel B, Harteneck C, Foerster J, Schultz G, Koesling D. Functions of conserved cysteines of soluble guanylyl cyclase. Biochemistry. 1997;36(6):1194-1198.

21. Warner TD, Mitchell JA, Sheng H, Murad F. Effects of cyclic GMP on smooth muscle relaxation. Adv Pharmacol. 1994;26:171-194.

22. Sanders KM, Ward SM, Thornbury KD, Dalziel HH, Westfall DP, Carl A. Nitric oxide as a non-adrenergic, non-cholinergic neurotransmitter in the gastrointestinal tract. Jpn J Pharmacol. 1992;58(suppl 2): 220-225.

23. Munzel T, Feil R, Mulsch A, Lohmann SM, Hofmann F, Walter U. Physiology and pathophysiology of vascular signaling controlled by guanosine $3^{\prime}, 5^{\prime}$-cyclic monophosphate-dependent protein kinase [corrected]. Circulation. 2003;108(18):2172-2183. 
24. Follmann M, Griebenow N, Hahn MG, et al. The chemistry and biology of soluble guanylate cyclase stimulators and activators. Angew Chem Int Ed Engl. 2013;52(36):9442-9462.

25. Stasch JP, Hobbs AJ. NO-independent, haem-dependent soluble guanylate cyclase stimulators. Handb Exp Pharmacol. 2009;191:277-308.

26. Ghofrani HA, Humbert M, Langleben D, et al. Riociguat: mode of action and clinical development in pulmonary hypertension. Chest. 2017;151(2):468-480.

27. Lang M, Kojonazarov B, Tian X, et al. The soluble guanylate cyclase stimulator riociguat ameliorates pulmonary hypertension induced by hypoxia and SU5416 in rats. PLoS One. 2012;7(8):e43433.

28. Schermuly RT, Stasch JP, Pullamsetti SS, et al. Expression and function of soluble guanylate cyclase in pulmonary arterial hypertension. Eur Respir J. 2008;32(4):881-891.

29. Geschka S, Kretschmer A, Sharkovska Y, et al. Soluble guanylate cyclase stimulation prevents fibrotic tissue remodeling and improves survival in salt-sensitive Dahl rats. PLoS One. 2011;6(7):e21853.

30. Ott IM, Alter ML, von Websky K, et al. Effects of stimulation of soluble guanylate cyclase on diabetic nephropathy in diabetic eNOS knockout mice on top of angiotensin II receptor blockade. PLoS One. 2012;7(8):e42623.

31. Sharkovska Y, Kalk P, Lawrenz B, et al. Nitric oxide-independent stimulation of soluble guanylate cyclase reduces organ damage in experimental low-renin and high-renin models. J Hypertens. 2010;28(8): $1666-1675$.

32. Methner $\mathrm{C}$, Buonincontri $\mathrm{G}, \mathrm{Hu} \mathrm{CH}$, et al. Riociguat reduces infarct size and post-infarct heart failure in mouse hearts: insights from MRI/ PET imaging. PLoS One. 2013;8(12):e83910.

33. Frey R, Mück W, Unger S, Artmeier-Brandt U, Weimann G, Wensing G. Single-dose pharmacokinetics, pharmacodynamics, tolerability, and safety of the soluble guanylate cyclase stimulator BAY 63-2521: an ascending-dose study in healthy male volunteers. $J$ Clin Pharmacol. 2008;48(8):926-934.

34. Bayer AG. Adempas $\odot$ (riociguat tablets) [US prescribing information]; Available from: http://labeling.bayerhealthcare.com/html/products/pi/ Adempas_PI.pdf. Revised: January 2017. Accessed February 6, 2017.

35. Bayer AG. Adempas $\subseteq$ (riociguat tablets) EU Summary of Product Characteristics. Available from: http://www.ema.europa.eu/docs/en_GB/ document_library/EPAR_-_Product_Information/human/002737/ WC500165034.pdf. Accessed February 6, 2017.

36. Grimminger F, Weimann G, Frey R, et al. First acute haemodynamic study of soluble guanylate cyclase stimulator riociguat in pulmonary hypertension. Eur Respir J. 2009;33(4):785-792.

37. Becker C, Frey R, Hesse C, Unger S, Reber M, Mück W. Absorption of riociguat (BAY 63-2521): bioavailability, food effects, and dose proportionality. Pulm Circ. 2016;6(S1):S27-S34.

38. Frey R, Becker C, Unger S, Schmidt A, Wensing G, Mück W. Assessment of the effects of hepatic impairment and smoking on the pharmacokinetics of a single oral dose of the soluble guanylate cyclase stimulator riociguat (BAY 63-2521). Pulm Circ. 2016;6(S1):S5-S14.

39. Ghofrani HA, Hoeper MM, Halank M, et al. Riociguat for chronic thromboembolic pulmonary hypertension and pulmonary arterial hypertension: a phase II study. Eur Respir J. 2010;36(4):792-799.

40. Saleh S, Becker C, Frey R, Mück W. Population pharmacokinetics and the pharmacokinetic/pharmacodynamic relationship of riociguat in patients with pulmonary arterial hypertension or chronic thromboembolic pulmonary hypertension. Pulm Circ. 2016;6(S1):S86-S96.

41. Frey R, Saleh S, Becker C, Mück W. Effects of age and gender on the pharmacokinetics of the soluble guanylate cyclase stimulator riociguat (BAY 63-2521). Pulm Circ. 2016;6(S1):S58-S65.

42. Czekaj P, Wiaderkiewicz A, Florek E, Wiaderkiewicz R. Tobacco smoke-dependent changes in cytochrome P450 1A1, 1A2, and 2E1 protein expressions in fetuses, newborns, pregnant rats, and human placenta. Arch Toxicol. 2005;79(1):13-24.

43. Galiè N, Grimminger F, Grünig E. Comparison of hemodynamic parameters in treatment-naïve and pretreated patients with pulmonary arterial hypertension in the randomized Phase III PATENT-1 study. Journal of Heart and Lung Transplantation. Epub 2016 Dec 24.
44. Galiè N, Grimminger F, Grünig E, et al. Correlation of improvements in hemodynamics and exercise capacity in patients with PAH: results from the phase III PATENT-1 study [abstract]. European Respiratory Journal. 2013;42(Suppl 57):1784.

45. Ghofrani HA, Galiè N, Grimminger F, et al. Riociguat for the treatment of pulmonary arterial hypertension. $N$ Engl J Med. 2013;369(4): 330-340.

46. Frey R, Mück W, Kirschbaum N, Kratzschmar J, Weimann G, Wensing G. Riociguat (BAY 63-2521) and warfarin: a pharmacodynamic and pharmacokinetic interaction study. J Clin Pharmacol. 2011;51(7):1051-1060.

47. Rubin LJ, Galiè N, Grimminger F, et al. Riociguat for the treatment of pulmonary arterial hypertension: a long-term extension study (PATENT-2). Eur Respir J. 2015;45(5):1303-1313.

48. Rickert V, Haefeli WE, Weiss J. Pharmacokinetic interaction profile of riociguat, a new soluble guanylate cyclase stimulator, in vitro. Pulm Pharmacol Ther. 2014;28(2):130-137.

49. Becker C, Frey R, Unger S, Artmeier-Brandt U, Weimann G, Mück W. Effects of omeprazole and aluminum hydroxide/magnesium hydroxide on riociguat absorption. Pulm Circ. 2016;6(suppl 1):S43-S48.

50. Simonneau G, D'Armini AM, Ghofrani HA, et al. Riociguat for the treatment of chronic thromboembolic pulmonary hypertension: a long-term extension study (CHEST-2). Eur Respir J. 2015;45(5):1293-1302.

51. Simonneau G, D'Armini AM, Ghofrani HA, et al. Predictors of longterm outcomes in patients treated with riociguat for chronic thromboembolic pulmonary hypertension: data from the CHEST-2 open-label, randomised, long-term extension trial. Lancet Respir Med. 2016;4(5): 372-380.

52. Minai OA, Bonner N, Odufowora O, et al. Health outcome assessment in chronic thromboembolic pulmonary arterial hypertension patients treated with riociguat: 2-year results from the CHEST-2 long term extension study. Am J Respir Crit Care Med. 2015;191:A4848

53. Condliffe R, Kiely DG, Gibbs JS, et al. Prognostic and aetiological factors in chronic thromboembolic pulmonary hypertension. Eur Respir J. 2009;33(2):332-338.

54. Jais X, D'Armini AM, Jansa P, et al; Bosentan Effects in iNopErable Forms of chronIc Thromboembolic pulmonary hypertension Study Group. Bosentan for treatment of inoperable chronic thromboembolic pulmonary hypertension: BENEFiT (Bosentan Effects in iNopErable Forms of chronIc Thromboembolic pulmonary hypertension), a randomized, placebo-controlled trial. J Am Coll Cardiol. 2008;52(25): 2127-2134.

55. Langleben D, Galie N, He J, et al. Use of clinically relevant responder threshold criteria to evaluate the response to treatment in the phase III PATENT-1 study. J Heart Lung Transplant. 2015;34(3):338-347.

56. Galiè N, Muller K, Scalise AV, Grunig E. PATENT PLUS: a blinded, randomised and extension study of riociguat plus sildenafil in PAH. Eur Respir J. 2015;45(5):1314-1322.

57. Ghofrani HA, Grimminger F, Grunig E, et al. Predictors of long-term outcomes in patients treated with riociguat for pulmonary arterial hypertension: data from the PATENT-2 open-label, randomised, long-term extension trial. Lancet Respir Med. 2016;4(5):361-371.

58. Barst RJ, Rubin LJ, Long WA, et al; Primary Pulmonary Hypertension Study Group. A comparison of continuous intravenous epoprostenol (prostacyclin) with conventional therapy for primary pulmonary hypertension. N Engl J Med. 1996;334(5):296-302.

59. Galie N, Olschewski H, Oudiz RJ, et al. Ambrisentan for the treatment of pulmonary arterial hypertension: results of the ambrisentan in pulmonary arterial hypertension, randomized, double-blind, placebocontrolled, multicenter, efficacy (ARIES) study 1 and 2. Circulation. 2008;117(23):3010-3019.

60. Galiè N, Ghofrani HA, Torbicki A, et al; Sildenafil Use in Pulmonary Arterial Hypertension (SUPER) Study Group. Sildenafil citrate therapy for pulmonary arterial hypertension. $N$ Engl J Med. 2005; 353(20):2148-2157.

61. Galiè N, Brundage BH, Ghofrani HA, et al; Pulmonary Arterial Hypertension and Response to Tadalafil (PHIRST) Study Group. Tadalafil therapy for pulmonary arterial hypertension. Circulation. 2009; 119(22):2894-2903. 
62. Olschewski H, Simonneau G, Galiè N, et al; Aerosolized Iloprost Randomized Study Group. Inhaled iloprost for severe pulmonary hypertension. N Engl J Med. 2002;347(5):322-329.

63. Rubin LJ, Badesch DB, Barst RJ, et al. Bosentan therapy for pulmonary arterial hypertension. $N$ Engl J Med. 2002;346(12):896-903.

64. Gabler NB, French B, Strom BL, et al. Validation of 6-minute walk distance as a surrogate end point in pulmonary arterial hypertension trials. Circulation. 2012;126(3):349-356.

65. Gilbert C, Brown MC, Cappelleri JC, Carlsson M, McKenna SP. Estimating a minimally important difference in pulmonary arterial hypertension following treatment with sildenafil. Chest. 2009;135(1):137-142.

66. Mathai SC, Puhan MA, Lam D, Wise RA. The minimal important difference in the 6-minute walk test for patients with pulmonary arterial hypertension. Am J Respir Crit Care Med. 2012;186(5):428-433.

67. Galiè N, Simonneau G, Barst RJ, Badesch D, Rubin L. Clinical worsening in trials of pulmonary arterial hypertension: results and implications. Curr Opin Pulm Med. 2010;16(suppl 1):S11-S19.

68. Benza RL, Seeger W, McLaughlin VV, et al. Long-term effects of inhaled treprostinil in patients with pulmonary arterial hypertension: the treprostinil sodium inhalation used in the management of pulmonary arterial hypertension (TRIUMPH) study open-label extension. J Heart Lung Transplant. 2011;30(12):1327-1333.

69. Oudiz RJ, Galiè N, Olschewski H, et al; ARIES Study Group. Long-term ambrisentan therapy for the treatment of pulmonary arterial hypertension. J Am Coll Cardiol. 2009;54(21):1971-1981.

70. Provencher S, Sitbon O, Humbert M, Cabrol S, Jais X, Simonneau G. Long-term outcome with first-line bosentan therapy in idiopathic pulmonary arterial hypertension. Eur Heart J. 2006;27(5):589-595.

71. Bonderman D, Ghio S, Felix SB, et al. Riociguat for patients with pulmonary hypertension due to systolic left ventricular dysfunction: a phase IIb double-blind, randomized, placebo-controlled, dose-ranging hemodynamic study. Circulation. 2013;128(5):502-511.

72. Bonderman D, Pretsch I, Steringer-Mascherbauer R, et al. Acute hemodynamic effects of riociguat in patients with pulmonary hypertension associated with diastolic heart failure (DILATE-1): a randomized, double-blind, placebo-controlled, single-dose study. Chest. 2014; 146(5):1274-1285.

73. Hoeper MM, Halank M, Wilkens H, et al. Riociguat for interstitial lung disease and pulmonary hypertension: a pilot trial. Eur Respir J. 2013; 41(4):853-860.

74. Cottin V. Treatment of pulmonary hypertension in interstitial lung disease: do not throw out the baby with the bath water. Eur Respir J. 2013;41(4):781-783.
75. Nathan SD, Collard HR, Cottin V, et al. Baseline characteristics of patients enrolled in a prospective study of riociguat for pulmonary hypertension associated with idiopathic interstitial pneumonia (RISEIIP Study). Am J Respir Crit Care Med. 193;2016:A3984.

76. Bayer Corporation [webpage on the Internet]. Bayer terminates phase II study with riociguat in patients with pulmonary hypertension associated with idiopathic interstitial pneumonias. Available from: http://www.prnewswire.com/news-releases/bayer-terminates-phaseii-study-with-riociguat-in-patients-with-pulmonary-hypertensionassociated-with-idiopathic-interstitial-pneumonias-300267616.html. Accessed February 6, 2017.

77. European Medicines Agency. Adempas Not for Use in Patients with Pulmonary Hypertension Caused by Idiopathic Interstitial Pneumonia; EMA Recommendation Follows Early Termination of a Clinical Trial in These Patients. Available from: http://www.ema.europa.eu/docs/ en_GB/document_library/Press_release/2016/06/WC500209316.pdf. Accessed February 6, 2017.

78. Dumitrascu R, Weissmann N, Ghofrani HA, et al. Activation of soluble guanylate cyclase reverses experimental pulmonary hypertension and vascular remodeling. Circulation. 2006;113(2):286-295.

79. Lim CS, Kiriakidis S, Sandison A, Paleolog EM, Davies AH. Hypoxiainducible factor pathway and diseases of the vascular wall. J Vasc Surg. 2013;58(1):219-230.

80. Mitrovic V, Swidnicki B, Ghofrani A, et al. Acute hemodynamic response to single oral doses of BAY 60-4552, a soluble guanylate cyclase stimulator, in patients with biventricular heart failure. $B M C$ Pharmacol. 2009;9(supp1 1):51.

81. Evgenov OV, Zou L, Zhang M, et al. Nitric oxide-independent stimulation of soluble guanylate cyclase attenuates pulmonary fibrosis. $B M C$ Pharmacol. 2011;11(suppl 1):O9.

82. Dees C, Beyer C, Distler A, et al. Stimulators of soluble guanylate cyclase (sGC) inhibit experimental skin fibrosis of different aetiologies. Ann Rheum Dis. 2015;74(8):1621-1625.

83. Farkas L, Gauldie J, Voelkel NF, Kolb M. Pulmonary hypertension and idiopathic pulmonary fibrosis: a tale of angiogenesis, apoptosis, and growth factors. Am J Respir Cell Mol Biol. 2011;45(1):1-15.

84. Barnes J, Mayes MD. Epidemiology of systemic sclerosis: incidence, prevalence, survival, risk factors, malignancy, and environmental triggers. Curr Opin Rheumatol. 2012;24(2):165-170.

\section{Publish your work in this journal}

Drug Design, Development and Therapy is an international, peerreviewed open-access journal that spans the spectrum of drug design and development through to clinical applications. Clinical outcomes, patient safety, and programs for the development and effective, safe, and sustained use of medicines are the features of the journal, which

\section{Dovepress}

has also been accepted for indexing on PubMed Central. The manuscript management system is completely online and includes a very quick and fair peer-review system, which is all easy to use. Visit http://www.dovepress.com/testimonials.php to read real quotes from published authors. 